\title{
The Second RNA Chaperone, Hfq2, Is Also Required for Survival under Stress and Full Virulence of Burkholderia cenocepacia J2315
}

\author{
Christian G. Ramos, Sílvia A. Sousa, André M. Grilo, Joana R. Feliciano, and Jorge H. Leitão* \\ IBB - Institute for Biotechnology and Bioengineering, Centre for Biological and Chemical Engineering, \\ Instituto Superior Técnico, Av. Rovisco Pais, 1049-001 Lisbon, Portugal
}

Received 18 November 2010/Accepted 19 January 2011

\begin{abstract}
Burkholderia cenocepacia $\mathbf{J} 2315$ is a highly virulent and epidemic clinical isolate of the $B$. cepacia complex (Bcc), a group of bacteria that have emerged as important pathogens to cystic fibrosis patients. This bacterium, together with all Bcc strains and a few other prokaryotes, is unusual for encoding in its genome two distinct and functional Hfq-like proteins. In this work, we show results indicating that the 188-amino-acid Hfq 2 protein is required for the full virulence and stress resistance of $\boldsymbol{B}$. cenocepacia $\mathrm{J} 2315$, despite the presence on its genome of the functional 79-amino-acid Hfq protein encoded by the $h f q$ gene. Similar to other Hfq proteins, Hfq2 is able to bind RNA. However, Hfq2 is unique in its ability to apparently form trimers in vitro. Maximal transcription of $h f q$ was observed in B. cenocepacia $\mathbf{J} 2315$ cells in the early exponential phase of growth. In contrast, $h f q 2$ transcription reached maximal levels in cells in the stationary phase, depending on the CepR quorum-sensing regulator. These results suggest that tight regulation of the expression of these two RNA chaperones is required to maximize the fitness and virulence of this bacterium. In addition, the ability of $\mathrm{Hfq} 2$ to bind DNA, not observed for Hfq, suggests that Hfq 2 might play additional roles besides acting as an RNA chaperone.
\end{abstract}

The RNA chaperone Hfq was initially identified as a protein required for RNA bacteriophage $\mathrm{Q}_{\beta}$ replication in Escherichia coli (13). Subsequently, this mediator of small noncoding RNA (sRNA)-mRNA interactions has gained further relevance due to its role as a master regulator of bacterial metabolism (39).

Much of the knowledge about the roles played by Hfq proteins comes from studies with Salmonella (25). Hfq proteins control the translation and decay of several mRNAs (21). The protein forms hexamers that bind preferentially to A/U-rich sequences of RNAs, mediating the interaction of sRNAs with their target mRNAs, thus modifying mRNA translation and/or stability $(9,39)$.

Several sRNAs that specifically bind to the Hfq protein have been shown to control the translation of their target mRNAs in response to environmental stresses (9). In addition, accumulating evidence indicates that the expression of some virulence genes depends on the presence of a functional Hfq protein. In a recent paper, Chao and Vogel reviewed the roles played by Hfq in several Gram-negative and Gram-positive pathogens. These roles include the control of toxin production, biofilm formation, quorum-sensing regulators, and type III secretion systems, among others (7).

The Burkholderia cepacia complex (Bcc) is a group of at least 17 closely related species that emerged in the 1980s as lifethreatening and difficult-to-eradicate pathogens among patients suffering from cystic fibrosis (CF) (10). More recently, these pathogens have also been recognized as important

\footnotetext{
* Corresponding author. Mailing address: Institute for Biotechnology and Bioengineering, Centre for Biological and Chemical Engineering, Instituto Superior Técnico, Torre Sul, Piso 6. Av. Rovisco Pais, 1049-001 Lisbon, Portugal. Phone: 351 218417688. Fax: 351218419199. E-mail: jorgeleitao@ist.utl.pt.

${ }^{\nabla}$ Published ahead of print on 28 January 2011.
}

threats to hospitalized patients suffering from other diseases $(18,35)$.

Several prokaryotes harbor genes encoding two distinct Hfq-like proteins in their genomes. This is the case for the archaeal species Methanobacterium thermautotrophicum and Archaeoglobus fulgidus, the bacterial species Bacillus anthracis, Magnetospirillum magnetotacticum, and Novosphingobium aromaticivorans, and several species of the Burkholderia genus, including all of the members of the Bcc (29).

In a previous work, we performed a functional analysis of the B. cepacia $h f q$ gene, which encodes a 79-amino-acid protein, and identified the $h f q 2$ gene, which encodes an unusually long Hfq-like protein composed of 188 amino acid residues (36).

In this report, we describe the functional analysis of the sRNA chaperones Hfq and Hfq2 from the highly virulent clinical isolate $B$. cenocepacia $\mathrm{J} 2315$ and compare the transcription patterns of $h f q$ and $h f q 2$ in cells in different growth phases. Results are also presented showing the requirement of both functional RNA chaperones, Hfq and Hfq2, for B. cenocepacia $\mathrm{J} 2315$ optimal survival of stress and for full virulence.

\section{MATERIALS AND METHODS}

Bacterial strains, culture conditions, plasmids, and primers. The bacterial strains and plasmids used in this study are described in Table 1. The primers and oligonucleotides used are listed in Table 2. B. cenocepacia strains were maintained on PIA (Pseudomonas isolation agar) plates supplemented with $700 \mu \mathrm{g}$ $\mathrm{ml}^{-1}$ trimethoprim for the $B$. cenocepacia $\mathrm{CJ} 1$ mutant or $B$. cenocepacia strains transformed with pMLBAD derivatives. B. cenocepacia H111-R $(\Delta c e p R)$ was maintained on PIA plates supplemented with $50 \mu \mathrm{g} \mathrm{ml}^{-1}$ kanamycin. E. coli strains were maintained on LB (Lennox broth) plates supplemented with antibiotics when appropriate. Liquid cultures were grown at $37^{\circ} \mathrm{C}$ in $\mathrm{LB}$ liquid medium supplemented with antibiotics when appropriate with orbital agitation (250 rpm). Plasmids pMLBAD, pSAS3, and pCGR9 were used in complementation experiments. Plasmid pCGR9 was obtained by ligating to BamHI/SalIdigested pMLBAD the BamHI/SalI-digested 595-bp amplimer obtained by PCR with primers UP-HF2-C and Low-HF2-C (Table 2) using B. cenocepacia J2315 
TABLE 1. Bacterial strains and plasmids used in this work

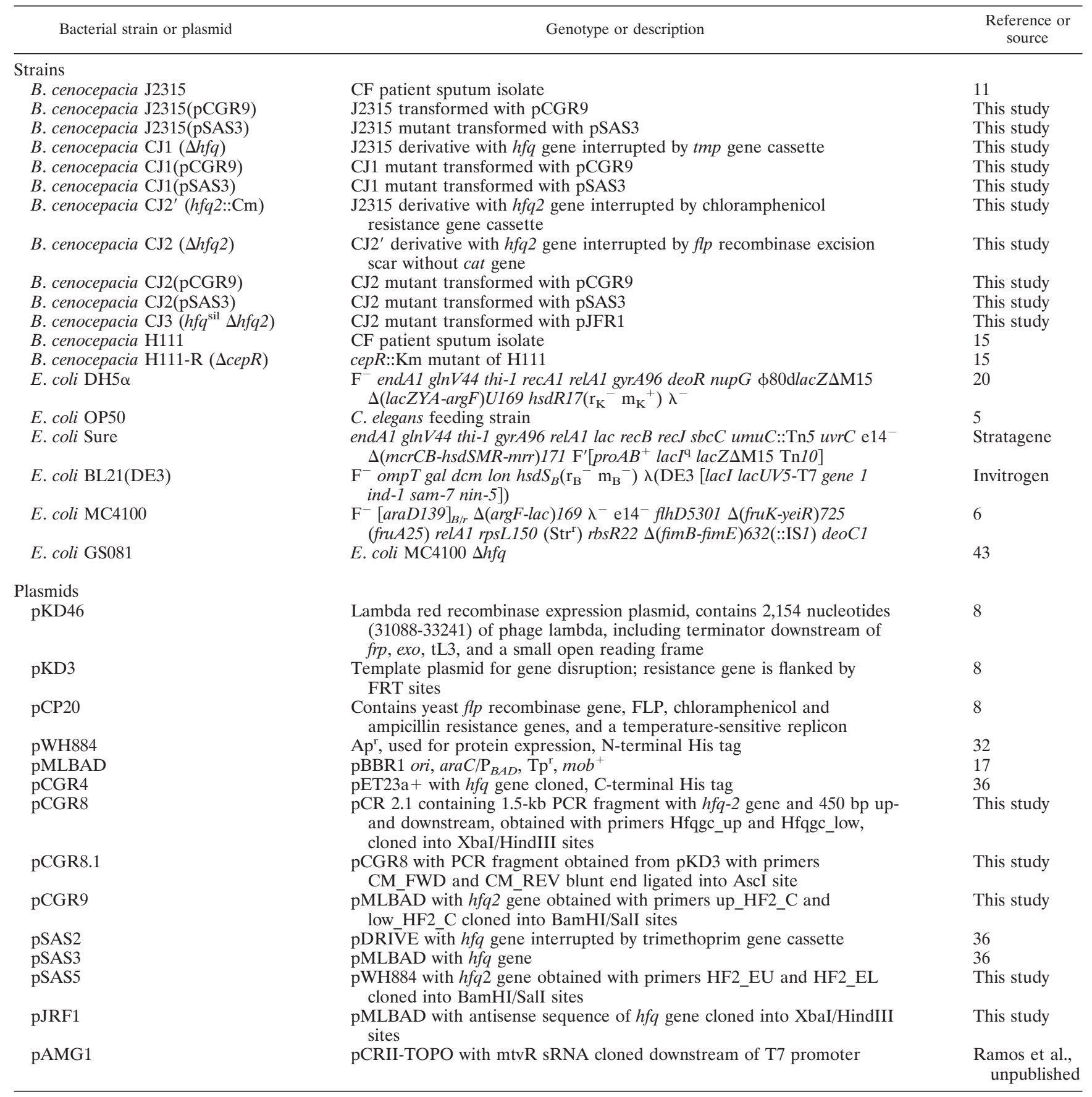

chromosomal DNA as the template. Plasmid pJRF1 was obtained by subcloning the HindIII-XbaI fragment of the $h f q$ gene from pSAS3 and ligating it into the XbaI-HindIII sites of pMLBAD. The resulting plasmid, pJRF1, expresses an antisense RNA, under the control of the $\mathrm{P}_{B A D}$ promoter, that is complementary to the $h f q$ mRNA, thus silencing $h f q$ by induction with arabinose. Plasmids were introduced into $B$. cenocepacia $\mathrm{CJ} 2$ by electroporation as previously described (34). Plasmid pSAS2 was used to construct the B. cenocepacia CJ1 mutant. Plasmid pSAS5 (Table 1), obtained by ligating the BamHI/SalI-digested PCR amplimer obtained with primers HF2_EU and HF2_EL (Table 2) to the BamHI/ SalI sites of pWH884, was used to express Hfq2 as an N-terminally His-tagged derivative.
DNA manipulation techniques. Total DNA was extracted from cells of exponentially growing liquid cultures of $B$. cenocepacia strains using the DNeasy Blood \& Tissue kit (Qiagen). Plasmid isolation and purification, DNA hydrolysis with restriction enzymes (Clontech-Takara), electrophoresis in agarose gels, DNA ligation, and E. coli transformations were carried out using standard procedures (30). Amplification of the $h f q$ or $h f q 2$ gene of B. cenocepacia $\mathrm{J} 2315$ in reverse transcription (RT)-PCR experiments was achieved with primers $\mathrm{Hfq} 2 \mathrm{cFWD}$ and $\mathrm{Hfq} 2 \mathrm{cREV}$ or $\mathrm{Hfq} \mathrm{Cu}$ and $\mathrm{Hfq} \mathrm{Cd}$, respectively (Table 2). $B$. cenocepacia CJ2 was generated using the lambda red helper plasmid (8). Briefly, plasmid pCGR8 was obtained by TA ligation to pCR2.1 of the $2.0-\mathrm{kb}$ PCR product obtained with B. cenocepacia J2315 chromosomal DNA as the template 
TABLE 2. Oligonucleotides and primers used in this work

\begin{tabular}{|c|c|c|c|c|}
\hline Name & Sequence $\left(5^{\prime}-3^{\prime}\right)^{a}$ & Purpose & $\begin{array}{l}\text { Restriction } \\
\text { site }\end{array}$ & Source \\
\hline Up_HF2_C & AGGATCCATGGCCAATCCCGCAGA & \multirow[t]{2}{*}{ Complementation experiments } & BamHI & This study \\
\hline Low_HF 2 _C & TTGTCGACTTACTGGCCGTCCG & & SalI & This study \\
\hline Hfq2c_FWD & AGGATCCATGGCCAATCCCGCAGA & \multirow[t]{2}{*}{ RT-PCR } & BamHI & This study \\
\hline Hfq2c_Rev & TAAGCTTCTGGCCGTCCGGCAC & & HindIII & This study \\
\hline Hfqgc_up & AATCTAGATGAGCCATATGACG & $h f q 2$ mutagenesis & $\mathrm{XbaI}$ & This study \\
\hline HF2_EU & AAGGATCCATGGCCAATCCCGCAGA & \multirow[t]{2}{*}{$h f q 2$ overexpression } & BamHI & This study \\
\hline $\mathrm{HF} 2-\mathrm{EL}$ & TT $\overline{\text { GTCGACTTACTGGCCGTCCG }}$ & & SalI & This study \\
\hline Hfq_Cu & GAATTCATGAGCAACAAAGG & RT-PCR & EcoRI & \\
\hline Hfq_Cd & TTTGCGATCTCGAGGGGACGA & RT-PCR & Xhol & \\
\hline HFQ2 & TACGGCTCCCGCGAGCCGCGTGAA & \multicolumn{2}{|l|}{$\begin{array}{l}\text { Northern analysis of } h f q \\
\text { Northern analysis of } h f q 2\end{array}$} & This study \\
\hline $5 \mathrm{~S}$ & TTCGGGATGGGAAGGGGTGGGA & \multicolumn{2}{|l|}{ Northern blot analysis loading control } & This study \\
\hline
\end{tabular}

${ }^{a}$ Restriction endonuclease recognition sequences are underlined.

and primers Hfqge_UP and Hfqge_LOW (Table 2). Plasmid pCGR8 was digested with SmaI, ethanol precipitated, and suspended in elution buffer $(10 \mathrm{mM}$ Tris, pH 8.0). Plasmid pKD3 (8) was used as a PCR template to obtain the chloramphenicol acetyltransferase (CAT) gene cassette with primers CM FWD and CM REV (Table 2) flanked by the FLP recombinase recognition site as previously described (8). The CAT resistance cassette was gel purified, filled in with the Klenow large fragment of DNA polymerase I (Invitrogen), and blunt end ligated to the digested pCGR8 plasmid, yielding pCGR8.1. All plasmid constructions were confirmed by nucleotide sequencing.

RT assays were performed using the Superscript one-step RT-PCR kit (Invitrogen) with appropriate gene-specific primers (Table 2).

Generation of mutants and confirmation of insertional inactivation by PCR. Plasmid pCGR8.1 was digested with EcoRI, and the 1.7-kb fragment corresponding to the 900-bp CAT element, the 580-bp $h f q 2$ gene, and the 220-bp $h f q 2$ gene surrounding region was purified after agarose gel electrophoresis and resuspended in elution buffer (10 mM Tris, pH 8.0). Cells of B. cenocepacia J2315 transformed with lambda red helper plasmid pKD46 were grown at $30^{\circ} \mathrm{C}$ to an optical density at $600 \mathrm{~nm}\left(\mathrm{OD}_{600}\right)$ of $\sim 0.6 \mathrm{in} 5$-ml SOB (30) liquid cultures with $1.5 \mathrm{mg} \mathrm{ml}^{-1}$ ampicillin and $1 \%$ (wt/vol) L-arabinose. Cells were made electrocompetent and electrotransformed as previously described $(22,36)$ using $25-\mu l$ cell suspensions and 1 to $10 \mu \mathrm{g}$ of the 1.7-kb digestion product from pCGR8.1. After electroporation, $1 \mathrm{ml}$ of SOC (30) liquid medium was added to the cell suspension, followed by incubation for $4 \mathrm{~h}$ at $37^{\circ} \mathrm{C}$. The cell suspension was then spread onto the surfaces of PIA plates supplemented with $250 \mu \mathrm{g} \mathrm{ml}^{-1}$ chloramphenicol. $\mathrm{Cm}^{\mathrm{r}}$ transformants were made electrocompetent and transformed with plasmid pCP20. The resulting cell suspensions were incubated at $30^{\circ} \mathrm{C}$ for $4 \mathrm{~h}$ and then spread onto the surface of nonselective PIA and incubated overnight at $42^{\circ} \mathrm{C}$ for plasmid loss. Colonies were replica plated on PIA plates not supplemented or supplemented with $250 \mu \mathrm{g} \mathrm{ml}{ }^{-1}$ chloramphenicol. Colonies unable to grow in the presence of chloramphenicol were kept for further analysis.

To confirm the insertional inactivation of $h f q 2$ in B. cenocepacia J2315, two colony PCR experiments were performed. Primers Hfq2cFWD and Hfq2cREV were used to confirm the occurrence of a double-crossover recombination in the $h f q 2$ gene (with an expected size of 1,480 bp), while primers CM_FWD and CM_REV were used to confirm the loss of the CAT element from the chromosome of the B. cenocepacia $h f q 2$ insertional mutant. Additionally, the $h f q 2 \mathrm{mu}-$ tation and the cat excision were confirmed by nucleotide sequencing of the PCR product obtained with primers Hfq2cFWD and Hfq2cREV and the chromosomal DNA from the B. cenocepacia $h f q 2$ insertional mutant as the template. The deletion mutant was named CJ2. The B. cenocepacia J2315 hfq insertion mutant
(B. cenocepacia CJ1) was generated using pSAS2 (36) based on previously described methods (36).

A $\Delta h f q 2$ mutant with the $h f q$ gene silenced $\left(h f q^{\text {sil }}\right)$ was constructed by cloning the $h f q$ PCR product digested with XbaI/HindIII into the XbaI/HindIII sites of pMLBAD, yielding pJRF1, which, upon induction with arabinose, expresses part of the antisense transcript of $h f q$, thus blocking $h f q$ mRNA translation. pJRF1 was electroporated into B. cenocepacia $\mathrm{CJ} 2$, and transformants were selected on PIA plates supplemented with $700 \mu \mathrm{g} \mathrm{ml}{ }^{-1}$ trimethoprim. This conditional mutant strain $\left(h f q^{\text {sil }} \Delta h f q 2\right)$ was named B. cenocepacia CJ3.

Cloning, overexpression, and purification of the $h f q$ and $h f q 2$ gene products. The Hfq protein was produced as a C-terminally His-tagged derivative expressed in E. coli BL21(DE3) cells harboring pCGR4 (Table 1) based on previously described methodologies (36). Purified, His-tagged Hfq in hexameric form $\left(\mathrm{Hfq}_{6}\right.$ ) was dialyzed with $25 \mathrm{mM}$ Tris- $\mathrm{Cl}$ ( $\left.\mathrm{pH} 7.5\right)-150 \mathrm{mM} \mathrm{NaCl}-0.5 \mathrm{mM}$ EDTA (17).

The Hfq2 protein was overexpressed as a recombinant protein with six additional histidine residues at its $\mathrm{N}$ terminus in $E$. coli Sure cells harboring pSAS5 $(33,40)$. After purification by affinity chromatography, fractions containing Histagged Hfq2 were dialyzed overnight against Hfq storage buffer (36) or $20 \mathrm{mM}$ phosphate buffer ( $\mathrm{pH}$ 8.0) using a Slide-A-Lyzer cassette (Pierce) with a 10-kDa cutoff. Purified proteins (as judged by Coomassie staining of a sodium dodecyl sulfate-polyacrylamide gel electrophoresis [PAGE] gel) were analyzed by Western blotting based on the methods of Sousa et al. (36) using the Penta-His HRP Conjugate antibody (Qiagen) and TMB (Sigma) as the substrate.

RNA extraction and purification. Total RNA was obtained from cells of $B$. cenocepacia strains J2315, CJ1, CJ2, H111, and H111-R harvested by centrifugation at appropriate time points using the Ribopure RNA isolation kit (Ambion). RNA concentration was estimated in an ND 1000 spectrophotometer (Nanodrop). RNA quality was assessed by visual inspection after electrophoresis in agarose/formaldehyde denaturing gels.

Electrophoretic mobility shift assays (EMSAs). The 136-nucleotide small noncoding RNA mtvR (C. G. Ramos, A. M. Grilo, and J. H. Leitão, unpublished data) was used in EMSAs. For this purpose, mtvR was transcribed in vitro from the pAMG1 plasmid using the MegaShortScript kit (Ambion), purified from a 7 $\mathrm{M}$ urea-8\% polyacrylamide gel, and $5^{\prime}$ end labeled with fluorescein isothiocyanate (FITC)-12-UTP (Amersham) using T4 polynucleotide kinase (NEB). Samples were prepared in a total volume of $25 \mu \mathrm{l}$ of RNA binding buffer (36) containing $0,5,25$, or $50 \mathrm{pmol}$ of purified, His-tagged Hfq 2 or $0,0.1,1,5,25$, or $50 \mathrm{mM} \mathrm{Hfq}$ and $10 \mathrm{pmol}$ of FITC-labeled mtvR sRNA. Nonlabeled yeast tRNA (Ambion) was added in excess to each sample to minimize nonspecific binding. 
After incubation for $15 \mathrm{~min}$ at $30^{\circ} \mathrm{C}$, the mixtures were loaded onto a $10 \%$ polyacrylamide gel in $1 \times$ Tris-borate-EDTA (TBE) buffer containing $1 \%$ (vol/ vol) glycerol. Electrophoresis was performed at $4^{\circ} \mathrm{C}$ and $150 \mathrm{~V}$ for $2 \mathrm{~h}$. RNAs were electroblotted at $200 \mathrm{~mA}$ for $1 \mathrm{~h}$ onto a BrightStar-Plus (Ambion) membrane soaked in $0.5 \times$ TBE and UV cross-linked. RNAs were detected by chemiluminescence using alkaline phosphatase-conjugated anti-FITC antibody (Amersham) in combination with the CDP-Star alkaline phosphatase substrate (Novagen).

Discontinuous native protein gel electrophoresis and circular dichroism (CD) experiments. Discontinuous native protein gel electrophoresis of purified, Histagged Hfq 2 was performed based on previously described methods (37). Briefly, aliquots of 20 - $\mu$ l protein samples $(6 \mu \mathrm{g})$ were added to $5 \mu \mathrm{l}$ of loading buffer (100 $\mathrm{mM}$ Tris-Cl [pH 8.0], 40\% glycerol, 0.5\% Brilliant Blue G) and incubated for 10 $\mathrm{min}$ at room temperature. To confirm the molecular mass of the Hfq2 oligomer, $20-\mu \mathrm{g}$ samples of the proteins aldolase $(158 \mathrm{kDa})$, bovine serum albumin (66 and $132 \mathrm{kDa})$, and ovalbumin (44 kDa) were used as molecular mass standards. The samples were visualized after $8 \%$ (wt/vol) discontinuous native PAGE (30) at $4^{\circ} \mathrm{C}$ and $100 \mathrm{~V}$ for $2 \mathrm{~h}$

CD spectroscopy experiments were performed using $36 \mu \mathrm{g}$ of purified, Histagged Hfq 2 in $20 \mathrm{mM}$ phosphate buffer ( $\mathrm{pH} 8.0$ ) and processed as previously described (3). The far UV CD spectrum was recorded at $25^{\circ} \mathrm{C}$ in a cell with a 1-mm path length using a PiStar-180 spectrometer (Applied Photophysics) at a scan speed of $60 \mathrm{~nm} / \mathrm{min}$, a time constant of $1 \mathrm{~s}$, and a bandwidth of $2 \mathrm{~nm}$. The neural network analysis method was used to estimate the Hfq 2 protein secondary structure from the far UV CD spectrum data (1). Results are the means of at least 10 wavelength scans.

Northern analysis. The levels of $h f q$ or $h f q 2$ mRNA were assessed by Northern blot analysis using $2 \mu \mathrm{g}$ of total RNA purified from cells harvested from cultures in different growth phases. Samples containing $2 \mu \mathrm{g}$ of total RNA were loaded into an $8 \mathrm{M}$ urea- $6 \%$ polyacrylamide gel and separated by electrophoresis in $1 \times$ TBE at a constant current of $35 \mathrm{~mA}$. After electrophoresis, total RNA was electrotransferred to a Hybond- $\mathrm{N}^{+}$membrane (Amersham) at $20 \mathrm{~V}$ for $16 \mathrm{~h}$ at $4^{\circ} \mathrm{C}$ using $0.5 \times \mathrm{TBE}$

Oligonucleotide probes (Table 2) were FITC labeled using the FluoresceinHigh Prime labeling kit (Roche) and purified using the Quick-Spin column for labeled DNA purification (Roche). Prehybridization and hybridization were performed as previously described $(14,16)$. The $5 \mathrm{~S}$ RNA was used as a loading control in all Northern blot experiments.

Hybridization signals were detected using a Typhoon 8600 variable-mode imager scanner (Amersham Biosciences Europe) after selecting the fluorescein emission laser, blue filter, 500-V excitation, and $200-\mu \mathrm{m}$ resolution. Relative mRNA abundance analysis was estimated with the UN-SCAN-IT gel software suite (Silk Scientific, Inc.) using the band intensities of the 5S RNA as a reference. Affinity constants $\left(K_{D}\right)$ were calculated by assuming a single binding site and using the equation $K_{D}=$ [protein-bound RNA]/[total RNA]

DNA binding experiments. The ability of Hfq 2 to bind DNA was assessed using gel shift assays as previously described (28). For this purpose, $100 \mathrm{fmol}$ of the FITC-labeled 124-bp DNA fragment (corresponding to part of the araC promoter and coding region) was obtained by restriction of plasmid pMLBAD with EcoRV and ClaI, followed by agarose gel electrophoresis, band excision, and purification with the NucleoSpin Extract II kit (Macherey-Nagel). The purified DNA fragments were incubated for $30 \mathrm{~min}$ at $25^{\circ} \mathrm{C}$ with His-tagged $\mathrm{Hfq}$ or Hfq2 $(0.2,1$, and $2 \mu \mathrm{M})$ in a total volume of $20 \mu \mathrm{l}$ of DNA binding buffer (28) supplemented with $1 \mathrm{mM}$ ATP and $100 \mathrm{nmol}$ of yeast tRNA (Ambion). Control experiments were performed using the DNA probe and $500 \mathrm{pM}$ Pbr (28). All mixtures contained $10 \mathrm{nmol}$ of the unlabeled 322-bp fragment obtained by pUC19 restriction with PvuII as competing nonlabeled DNA. After incubation, the reaction products were subjected to native $10 \% \mathrm{PAGE}$ at $4^{\circ} \mathrm{C}$ and $150 \mathrm{~V}$ for $3 \mathrm{~h}$. Retardation corresponding to DNA-protein complexes was detected using a Typhoon 8600 variable-mode imager scanner with the fluorescein emission laser, blue filter, 650-V excitation, and 200- $\mu \mathrm{m}$ resolution (Amersham Biosciences Europe). The affinity constant $\left(K_{D}\right)$ was calculated by assuming a single binding site and using the equation $K_{D}=$ [protein-bound DNA]/[total DNA].

Stress susceptibility experiments. The susceptibility of strains of B. cenocepacia (J2315, J2315 with plasmid pSAS3 or pCGR9, the CJ1 mutant, CJ1 with plasmid pSAS3 or pGCR9, the CJ2 mutant, CJ2 with plasmid pGCR9 or pSAS3, and the CJ3 mutant) and E. coli (MC4100, GS081, and GS081 with plasmid pSAS3 or pCGR9) to the stresses imposed by growth in solid LB medium containing $1 \%$ (wt/vol) L-arabinose and supplemented with $3 \%$ (wt/vol) $\mathrm{NaCl}$, $150 \mu \mathrm{M}$ methyl viologen ( $\mathrm{pH} 5.0$; [obtained with $100 \mathrm{mM}$ phosphate-buffered LB]), or growth at $42^{\circ} \mathrm{C}$ were performed as previously described (28). Results are the means of at least five independent experiments.
Nematode infection experiments. Nematode killing assays and nematode digestive tract bacterial colonization experiments were performed based on previously described methods (36) using Caenorhabditis elegans mutant strain DH26. Reported values are the means of triplicate results of at least three independent experiments using a nematode population of 1,250 \pm 25 worms. Nematodes were photographed at 24,48 , and $72 \mathrm{~h}$ postinfection (p.i.) to visually evaluate the condition of their health (magnification shown is $\times 40$ ).

Nucleotide and amino acid sequence analysis and structure predictions. $\mathrm{Nu}-$ cleotide and amino acid sequences were analyzed using bioinformatic tools available at the National Center for Biotechnology Information, the ExPaSy Prosite, or the European Bioinformatics Institute. The Virtual Footprint suite was used for promoter analysis (24) using Pseudomonas aeruginosa promoter sequences.

Statistical analysis. All of the data presented were subjected to a one-way analysis of variance of mean values. Error bars represent the standard deviation of the mean.

\section{RESULTS}

Two distinct $h f q$-like genes are found in B. cenocepacia $\mathbf{J} 2315$ chromosome I. In a previous work, we performed a functional analysis of the 79-amino-acid protein Hfq (BCAL1879 in the genome sequence of $B$. cenocepacia J2315, Fig. 1A) from the clinical isolate $B$. cepacia IST408 and described the identification of a second 188-amino-acid putative Hfq-like protein in $B$. cenocepacia J2315, Hfq2 (36), which was the focus of this work. The gene encoding Hfq2 (BCAL1538) is also located in chromosome I, about $370 \mathrm{~kb}$ from the gene for Hfq (Fig. 1B), and is flanked by genes encoding predicted membrane proteins, exported proteins, regulatory proteins, and an acyl coenzyme A (CoA) synthetase (Fig. 1B).

Inspection of the complete genomes of other members of the Bcc revealed that all encode proteins highly similar to $\mathrm{Hfq}$ and Hfq2. Moreover, these Hfq-like protein-encoding genes are located in similar loci (data not shown).

Construction of $\boldsymbol{h} f \boldsymbol{q}$ and $\boldsymbol{h} f \boldsymbol{2} \mathbf{2}$ B. cenocepacia $\mathrm{J} 2315$ mutants. In order to gain insights into the biological functions of this second Hfq-like protein, two mutant strains were constructed, $\mathrm{CJ} 2{ }^{\prime}$ and $\mathrm{CJ} 2$. CJ2' was derived from B. cenocepacia $\mathrm{J} 2315$ by the insertion of a cat gene flanked by FRT sites. CJ 2 was obtained by excision of the cat gene from $\mathrm{CJ} 2$ ', introducing three stop codons after nucleotide position 211, thus inactivating the $h f q 2$ gene. The $B$. cenocepacia $\mathrm{CJ} 1$ mutant was also constructed from $B$. cenocepacia $\mathrm{J} 2315$ by insertional inactivation of the $h f q$ gene with a trimethoprim resistance cassette (Fig. 1A and C) using plasmid pSAS2 and based on previously described methodologies (36). Despite several attempts to construct a $\Delta h f q \Delta h f q 2$ double mutant, we were not successful. Therefore, a conditional mutant with the $h f q$ gene silenced $\left(h f q^{\mathrm{sil}}\right)$ was obtained by introducing pJRF1 into $\Delta h f q 2$ mutant strain CJ2, yielding $h f q^{\text {sil }} \Delta h f q 2$ mutant strain CJ3. Upon induction with arabinose, an $h f q$ antisense RNA is expressed from plasmid pJRF1, thus silencing $h f q$ in the $\Delta h f q 2$ background. In order to confirm that the $h f q$ and $h f q 2$ genes were not expressed in the $\mathrm{CJ} 1$ and $\mathrm{CJ} 2^{\prime}$ mutants, respectively, total RNA was extracted from cells of wild-type strain $B$. cenocepacia J2315 and of the mutants CJ1 and CJ2' (before excision of the cat gene) and used in RT experiments. No amplification bands corresponding to the $h f q$ or $h f q 2$ mRNA could be detected for the B. cenocepacia $\mathrm{CJ} 1$ and $\mathrm{CJ} 2$ ' mutants, respectively, thus confirming the inactivation of the $h f q$ and $h f q 2$ genes (Fig. 2A). The CJ2 mutant was used thereafter to avoid effects due to the use of chloramphenicol. 

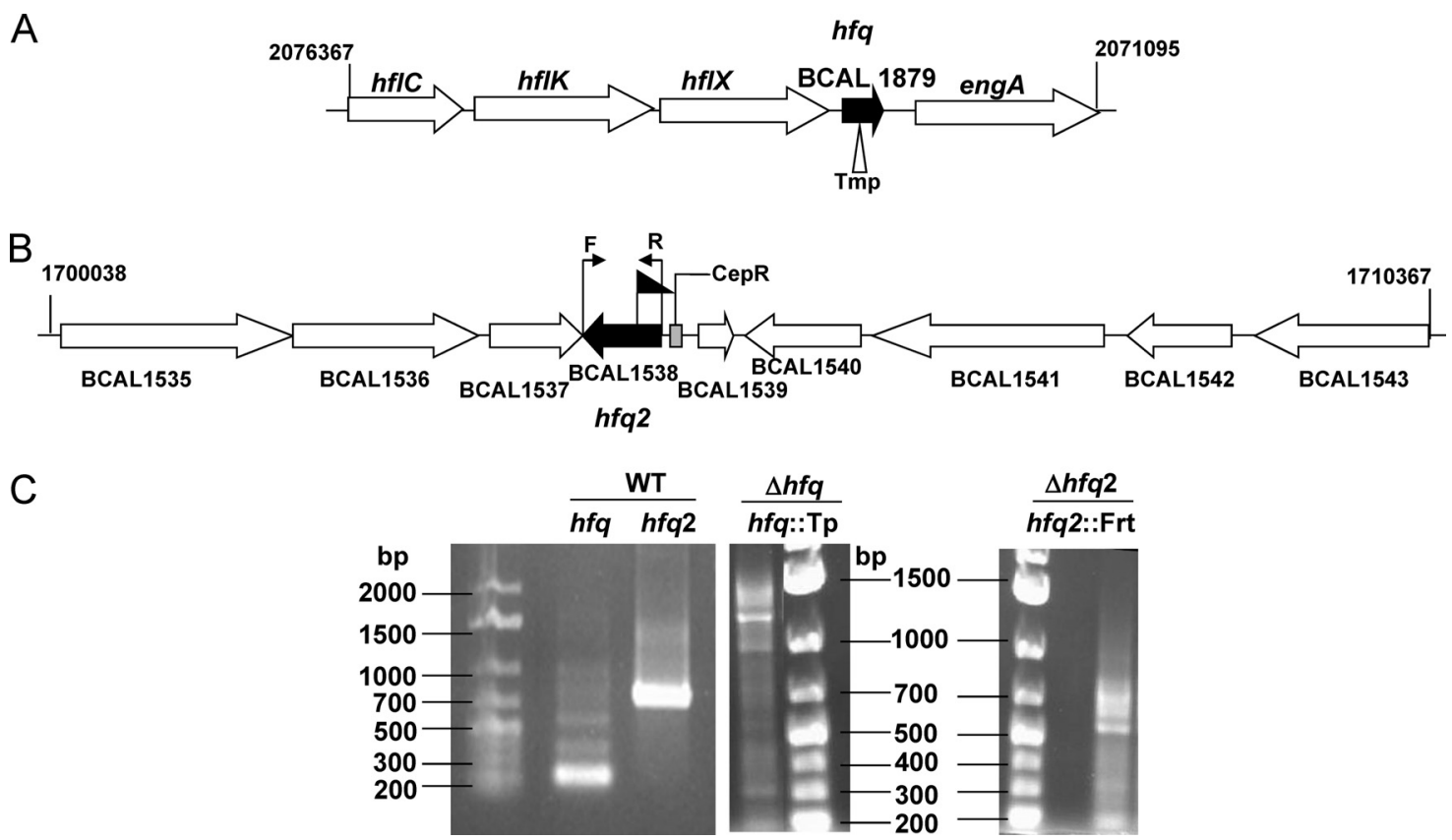

FIG. 1. Genetic organization of the $h f q$ and $h f q 2$ genes in B. cenocepacia J2315. (A) Genetic organization of the $h f q$ gene locus showing the trimethoprim (Tmp) cassette insertion. (B) Genetic organization of the $h f q 2$ gene locus. Open reading frames BCAL1535 (membrane protein with unknown function), BCAL1536 ( $\sigma^{54}$-dependent transcriptional regulator), BCAL1537 (putatively exported lipoprotein), BCAL1538 (Hfq2 chaperone), BCAL1539 (putative exported protein), BCAL1540 (transmembrane lipoprotein), BCAL1541 (acyl-CoA synthetase), BCAL1542 (TetR family regulatory protein), and BCAL1543 (major facilitator superfamily protein) are represented in scale. The positions of the three nonsense stop signals introduced after nucleotide 211 are indicated by the filled flag ( $h f q 2::$ Frt). Primers used in RT-PCR experiments are indicated by the letters F (Hfq2c_Fwd) and R (Hfq2c_Rev). The predicted CepR-dependent promoter is also indicated. (C) PCR amplification of the $h f q$ and $h f q 2$ genes from B. cenocepacia wild-type (WT) strain J2315 and mutant strains CJ1 $(\Delta h f q)$ and CJ2 $(\Delta h f q 2)$.

The $\boldsymbol{h} \boldsymbol{f} \boldsymbol{q}$ and $\boldsymbol{h} \boldsymbol{f} \boldsymbol{q} \mathbf{2}$ genes are differentially expressed. In order to gain further clues to the regulation of both the $h f q$ and the $h f q 2$ genes, we investigated their mRNA levels in B. cenocepacia strain $\mathrm{J} 2315$. The levels of mRNA corresponding to $h f q 2$ increased about 2-fold, reaching maximal values in cells in the stationary phase of growth (Fig. 2B). In contrast, the levels of mRNA corresponding to $h f q$ were maximal in cells in the early exponential phase of growth (Fig. 2B), decreasing almost 2.5fold in cells in the stationary phase (Fig. 2C).

The mRNA levels of $h f q 2$, but not $h f q$, are quorum sensing dependent. A bioinformatic search for putative promoter sequences upstream of the $h f q 2$ gene revealed a putative $l u x$ box-like consensus sequence located $50 \mathrm{bp}$ upstream of the $h f q 2$ gene ATG codon (Fig. 1B). In B. cenocepacia, CepR is a LuxR family transcription regulator which binds to lux box sequences (42). Therefore, we used total RNA extracted from the well-studied B. cenocepacia isolate $\mathrm{H} 111$ and its derivative cepR mutant in Northern blot experiments to assess the mRNA levels of $h f q 2$ in a cepR-defective mutant. As shown in Fig. 2C, the band corresponding to the $h f q 2$ mRNA is significantly weaker in the cepR mutant than in the B. cenocepacia H111 wild-type strain and is only detected at $24 \mathrm{~h}$ of growth.

The Hfq $2 \mathrm{C}$ terminus contains a repeated motif. Compared to the 79-amino-acid protein Hfq, which is $100 \%$ identical to the $B$. cepacia IST408 Hfq protein previously characterized by our research group (36), the B. cenocepacia J2315 Hfq 2 protein is 109 amino acid residues longer (with a total of 188 residues) (Fig. 3A). Alignment of the B. cenocepacia J2315 Hfq and Hfq 2 proteins and with other large Hfq proteins revealed that the two proteins share a significant level of conservation between residues 10 and 65 , with $60 \%$ identity and $75 \%$ similarity (Fig. 3B). The typical conserved core motifs of Hfq chaperones were also highly conserved in Hfq2, namely, the Sm1 and Sm2 motifs, structurally conserved loops 3 and 5, and RNA binding residues ${ }^{10} \mathrm{Gln},{ }^{62} \mathrm{Ile}$, and ${ }^{63} \mathrm{Ser}$ (Fig. 3A). The ${ }^{8} \mathrm{His},{ }^{9}$ Pro, ${ }^{10} \mathrm{Gln},{ }^{11} \mathrm{Asn},{ }^{62} \mathrm{Ile},{ }^{63} \mathrm{Ser},{ }^{64} \mathrm{Thr},{ }^{65} \mathrm{Ile}$, and ${ }^{66} \mathrm{Gln}$ residues in Hfq2, which are predicted to be involved in substrate binding, were conserved only in Hfq proteins from Burkholderia strains (Fig. 3A).

Interestingly, the C-terminal extension of $\mathrm{Hfq} 2$ and the $\mathrm{Hfq}$ homologues from $B$. cenocepacia $\mathrm{MCO}-3, B$. vietnamensis $\mathrm{G} 4$, and $B$. multivorans ATCC 17616 were all composed of a glycinerich region $\left({ }^{70} \mathrm{G}\right.$ to $\left.{ }^{173} \mathrm{G}\right)$, a putative DNA binding domain $\left({ }^{89} \mathrm{G}\right.$ to $\left.{ }^{129} \mathrm{E}\right)$, and the repetitive motif $\mathrm{RE}(\mathrm{P} / \mathrm{S}) \mathrm{RRXX}(\mathrm{E} / \mathrm{G})(\mathrm{G} / \mathrm{S})$, which occurs five times in Hfq2, as highlighted in Fig. 3A.

Hfq2 forms trimers in vitro. Secondary-structure predictions indicate that $6 \%$ of the amino acid residues of Hfq 2 fold into an $\alpha$-helix and $31 \%$ fold into a $\beta$-sheet. In loose agreement with these predictions, calculations performed based on $\mathrm{CD}$ spectroscopy results indicate that $B$. cenocepacia Hfq 2 is composed of $5 \% \alpha$-helix and $47 \% \beta$-sheet (Fig. 4A). This discrepancy probably derives from the fact that the computational structure prediction of $B$. cenocepacia J2315 Hfq2 was based on the 69-amino-acid crystal structure of the $E$. coli Hfq protein.

The ability of purified, His-tagged Hfq2 (Fig. 4B) to form multimeric structures was investigated by discontinuous native PAGE. A major band with approximately three times the mo- 

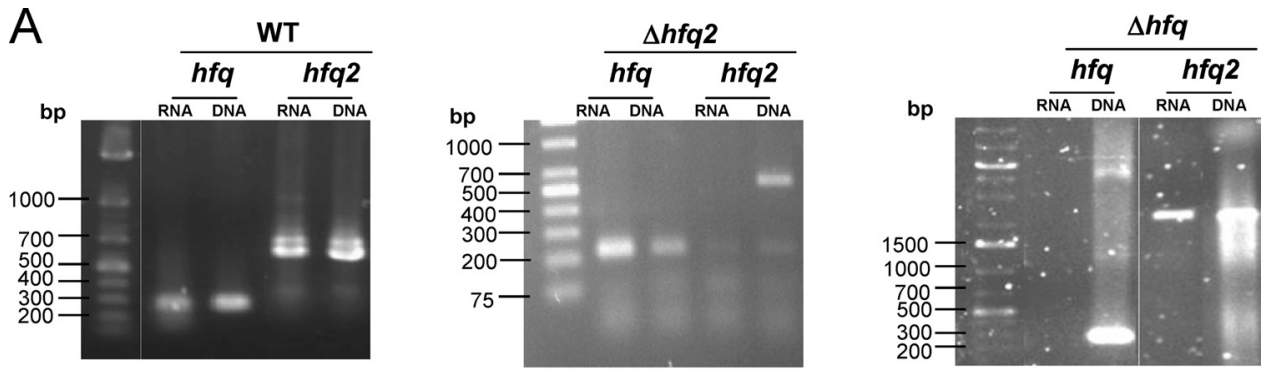

B

B. cenocepacia J2315

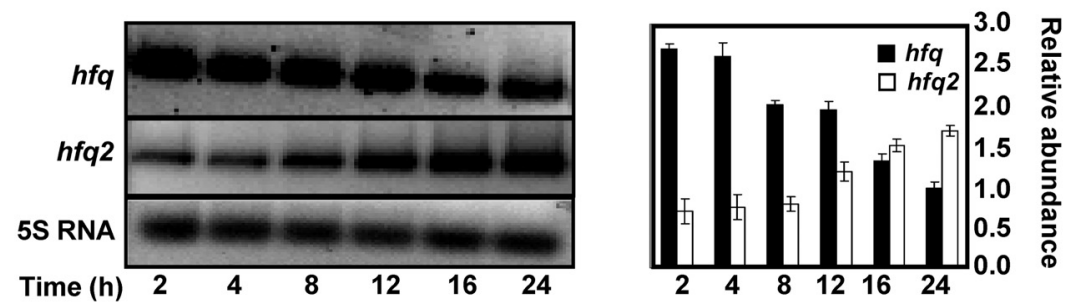

C

B. cenocepacia $\mathrm{H} 111$
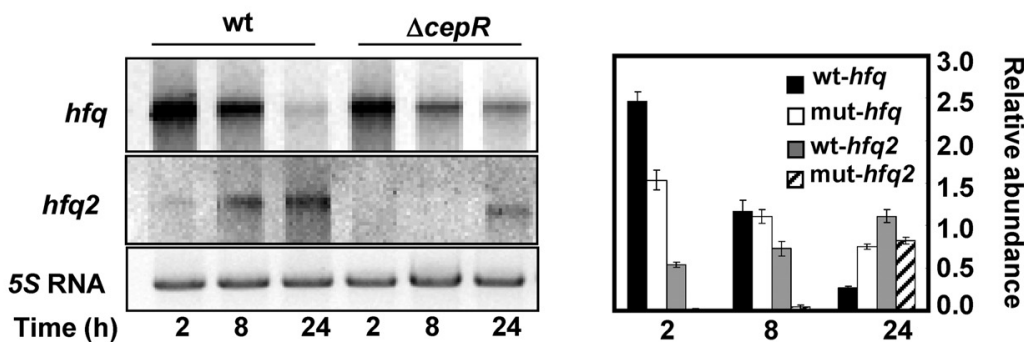

FIG. 2. Expression analysis of the $h f q$ and $h f q 2$ genes. (A) RT of $h f q$ and $h f q 2$ RNA samples obtained from cells of $B$. cenocepacia wild-type (WT) strain J2315 and the CJ1 $(\Delta h f q)$ and CJ2' ( $\Delta h f q 2)$ mutants. Control experiments were carried out using chromosomal DNA. (B) Northern blot analysis of mRNA corresponding to $h f q$ and $h f q 2$ in B. cenocepacia J2315. Relative abundance was quantified for both $h f q$ (black bars) and hfq2 (white bars) in B. cenocepacia J2315 using the RNA levels of the 5S rRNA as a control. Error bars represent the standard deviations of the means. (C) Detection of $h f q$ and $h f q 2$ mRNA levels in B. cenocepacia wild-type strain $\mathrm{H} 111$ and a cepR mutant strain by Northern blotting. Quantification of $h f q$ mRNA in the B. cenocepacia wild-type H111 (black bars) and $\Delta c e p R$ mutant (white bars) strains and of $h f q 2$ transcripts in the B. cenocepacia wild-type H111 (gray bars) and $\Delta c e p R$ mutant (dashed bars) strains was performed using the 5S rRNA mRNA levels as a control. All experiments were repeated at least three times.

lecular mass of monomeric Hfq2 suggests that the protein might exist as a trimer in its active/native form in vitro. This result contrasts with the findings for other Hfq proteins and the Hfq protein of B. cenocepacia J2315, which forms hexamers in vitro (36). A faint band, highlighted in Fig. 4B with an asterisk, with an apparent molecular mass compatible with a tetrameric form of Hfq2 was also observed. Nevertheless, the trimeric form is predominant.

B. cenocepacia J2315 Hfq and Hfq2 bind to the sRNA mtvR. Since both Hfq and Hfq 2 possess all of the motifs required for RNA binding, we tested their ability to bind the mtvR sRNA by using EMSAs. Results shown in Fig. 5 clearly show that both proteins are able to bind this sRNA. Interestingly, Hfq seems to bind mtvR more efficiently (60-fold lower $K_{D}$ ) than Hfq2 does.

Hfq2, but not Hfq, binds DNA. Since a DNA binding domain spanning amino acid residues 87 to 128 was bioinformatically predicted for Hfq2, we performed DNA binding assays. For this purpose, we used either purified, His-tagged Hfq or Hfq2 and the 124-bp EcoRV/ClaI DNA fragment of the araC promoter of pMLBAD (17). The purified, His-tagged Pbr regula- tory protein, which is involved in the regulation of $B$. cenocepacia K56-2 phenazine biosynthesis and cellular processes related to stress resistance and virulence (28), was used as a positive control. Results presented in Fig. 6 clearly show that Hfq2 is able to bind DNA, consistent with the predicted occurrence of a DNA binding domain. An apparent binding constant of $92 \mathrm{nM}$ for the Pbr regulator to the DNA fragment was estimated, while a value of $44.2 \mu \mathrm{M}$ was estimated for the binding of Hfq2 to this particular DNA fragment. Similar experiments performed using Hfq instead of Hfq2 did not reveal the binding of Hfq to this DNA fragment (data not shown). The biological significance of the ability of Hfq2 to bind DNA is unknown, although we speculate that the protein might act as a transcription regulator.

Hfq2 is required for resistance to stress. We compared the abilities of wild-type B. cenocepacia $\mathrm{J} 2315$ and its derivative mutants CJ1 and CJ2 (carrying nonfunctional $h f q$ and $h f q 2$ genes, respectively) to survive stress conditions mimicking those faced by the bacterium when colonizing/infecting the $\mathrm{CF}$ lung, namely, growth at $42^{\circ} \mathrm{C}$, oxidative stress conditions im- 
BCen J2315 Hfq Bcen_J2315 Hfq2 BCen $\mathrm{MCO} 3$ Hfq BvietG4 Hf̄g Bmul_ATCC 17616_Hfq Nmening $053442 \overline{\mathrm{H}} f q$ Mcatar $\mathrm{RH} 4 \mathrm{Hfq}$ Clustā Consensus

Bcen J2315 Hfq Bcen J2315 Hfq2 BCen ${ }^{-} \mathrm{MCO} 3 \overline{\mathrm{H}} \mathrm{fq}$ BviēG4 Hf̆g Bmul ATCC $17616 \mathrm{Hfq}$

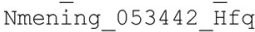
Mcatar $\bar{R} H 4$ Hfq Clustal Consensus

Bcen J2315 Hfq Bcen_J2315_Hfq2 BCen MCO3 $\bar{H} f q$ BvietG4 Hfq Bmul_ATCC 17616_Hfq Nmening $053442 \mathrm{Hfq}$ Mcatar $\mathrm{RH} 4 \mathrm{Hfq}$ Clustā Consensus

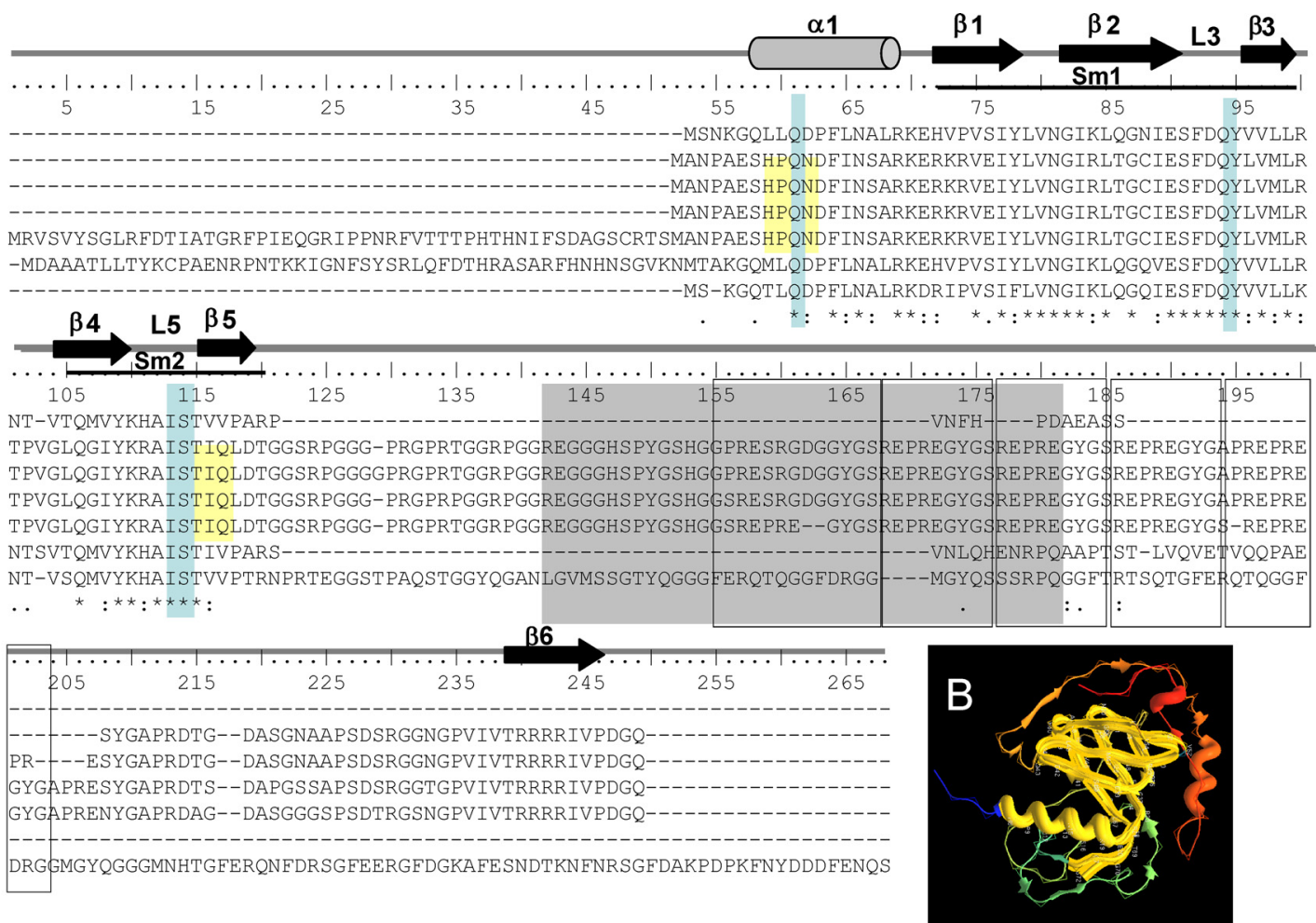

FIG. 3. Hfq2 is highly conserved within the Bcc. (A) Alignment of the B. cenocepacia J2315 Hfq and Hfq2 proteins with other Hfq-like proteins showing the predicted secondary structure of Hfq2 above the amino acid residues. The Sm1 and Sm 2 motifs are indicated. RNA binding domains are represented by blue boxes. Residues also predicted to be involved in RNA binding are highlighted in yellow. The DNA binding domain is within the gray box. Boxed sequences denote the identified repeats. Identical amino acid residues are marked with an asterisk, and conserved and semiconserved substitutions are marked with double and single dots, respectively. Abbreviations: Bcen, B. cenocepacia; Bviet, B. vietnamensis; Bmul, B. multivorans; Nmening, Neisseria meningitidis; Mcatar, Moraxella catarrhalis. (B) Superimposition of the monomeric predicted three-dimensional structures of Hfq and Hfq2 from B. cenocepacia J2315. The structural alignment is highlighted in yellow, with a root mean square deviation of $0.910 \AA$.

posed by methyl viologen, acidic $\mathrm{pH}$, and osmotic stress induced by the addition of $3 \% \mathrm{NaCl}$ to the culture medium. The $\mathrm{CJ} 3\left(h f q^{\text {sil }} \Delta h f q 2\right)$ strain was also included in this analysis. CJ3 carries a nonfunctional $h f q 2$ gene, and upon induction with L-arabinose, it expresses an antisense RNA targeting $h f q$. In comparison with wild-type strain $\mathrm{J} 2315$ overexpressing the $h f q$ or $h f q 2$ gene, the results clearly indicate that mutation of the $h f q$ or the $h f q 2$ gene rendered the respective strain CJ1 or CJ2 more susceptible to the tested stress. This indicates that both genes are required for optimal survival of various stresses (Fig. 7). The increased susceptibility of these mutants was at least partially rescued by the ectopic expression of $h f q$ or $h f q 2$. This
A

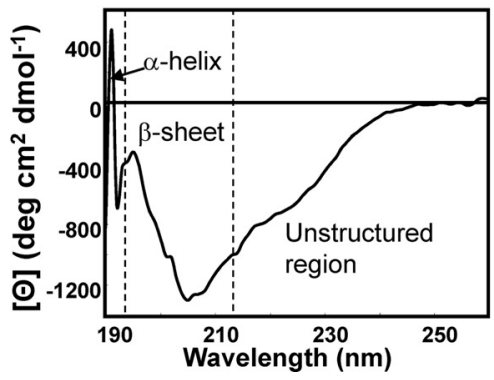

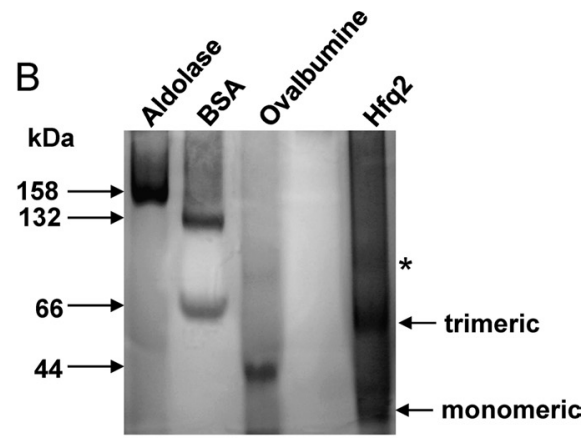

FIG. 4. Hfq2 forms trimeric structures in vitro. (A) Far UV CD spectrum of Hfq2 from B. cenocepacia J2315. The regions of the spectrum corresponding to the $\alpha$-helix and $\beta$-sheet are indicated. (B) Discontinuous native PAGE showing a predominant Hfq 2 band at $\sim 63 \mathrm{kDa}$ compatible with a trimeric form of the protein. The monomeric form is also visible. Possible higher-order complexes (marked by an asterisk) can be seen. BSA, bovine serum albumin. 


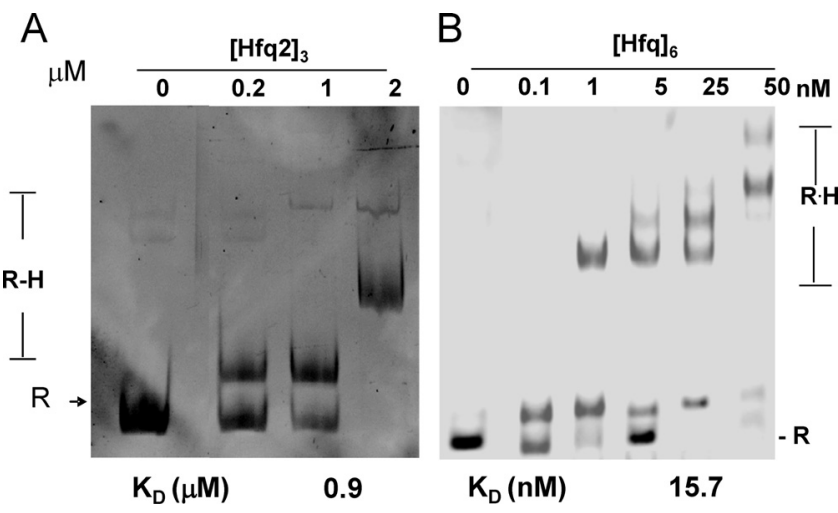

FIG. 5. B. cenocepacia J2315 Hfq2 is able to bind sRNAs (A) EMSA experiments using $0,0.2,1$, and $2 \mu \mathrm{M}$ purified, His-tagged

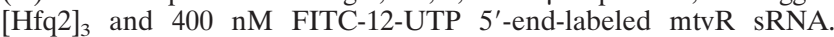
(B) With increasing $[\mathrm{Hfq}]_{6}$, additional $\mathrm{Hfq}$ multimers bind to the $\mathrm{mtvR}$ sRNA. [Hfq2 $]_{3}$, trimeric form of $\mathrm{Hfq} 2 ;[\mathrm{Hfq}]_{6}$, hexameric form of $\mathrm{Hfq}$; $\mathrm{R}-\mathrm{H}$, complexes formed by [Hfq 2$]_{3}$ and the mtvR sRNA; R.H, complexes formed by $[\mathrm{Hfq}]_{6}$ and the mtvR sRNA (R).

partial complementation has been observed before (28) and is derived from insufficient amounts of L-arabinose to fully induce the $\mathrm{P}_{B A D}$ promoter. Remarkably, the CJ3 strain exhibited the highest susceptibility to the stresses studied, reinforcing the observation that both the $h f q$ and $h f q 2$ genes are required for optimal survival of $B$. cenocepacia J2315 under stress conditions. Overexpression of $h f q$ rendered B. cenocepacia wild-type strain J2315 more resistant to methyl viologen and $\mathrm{NaCl}$, while overexpression of $h f q 2$ rendered the wild-type strain more resistant to growth at $42^{\circ} \mathrm{C}$ and $\mathrm{pH} 5.0$. Both the $h f q$ and $h f q 2$ genes of B. cenocepacia $\mathrm{J} 2315$ were used in complementation experiments with $E$. coli $h f q$ mutant strain GS081. Results shown in Fig. 8 indicate that both genes are functional in $E$. coli, being able to partially rescue the observed growth defects of the E. coli hfq mutant when it is exposed to oxidative stress imposed by methyl viologen. It is worth noting that $h f q 2$ was able to fully complement the ability of the E. coli $h f q$ mutant to grow at $42^{\circ} \mathrm{C}$ or $\mathrm{pH}$ 5.0. Remarkably, when $h f q 2$ was provided in trans to the E. coli $h f q$ mutant, this strain became less susceptible to the osmotic stress imposed by $3 \% \mathrm{NaCl}$, compared with E. coli wild-type strain MC4100.

$\boldsymbol{h} f \boldsymbol{q}$ and $\boldsymbol{h} f \boldsymbol{q} \mathbf{2}$ are both required for full virulence of $\boldsymbol{B}$. cenocepacia J2315. The role played by $h f q$ and $h f q 2$ in B. cenocepacia J2315 virulence using $C$. elegans as an infection model was investigated based on slow-killing assays (36). The abilities of wild-type B. cenocepacia J2315, $h f q$ mutant strain CJ1, $h f q 2$ mutant CJ2 strain, and the CJ3 antisense knockdown strain, as well as the wild-type strain overexpressing $h f q$ or $h f q 2$ in trans, to kill C. elegans larvae at the L4 stage were compared.

Results shown in Fig. 9A clearly indicate that overexpression of $h f q$ rendered the wild-type strain more virulent. This was also observed, although to a lesser extent, until the second day of infection by the wild-type strain overexpressing $h f q 2$. Compared to the wild-type strain, the $\mathrm{CJ} 3$ strain was significantly attenuated, and this effect was particularly evident at 3 or 4 days p.i. Figure 9 also clearly indicates that mutations in $h f q$ (panel B) or $h f q 2$ (panel C) significantly reduced the virulence of B. cenocepacia J2315. Although general overexpression of

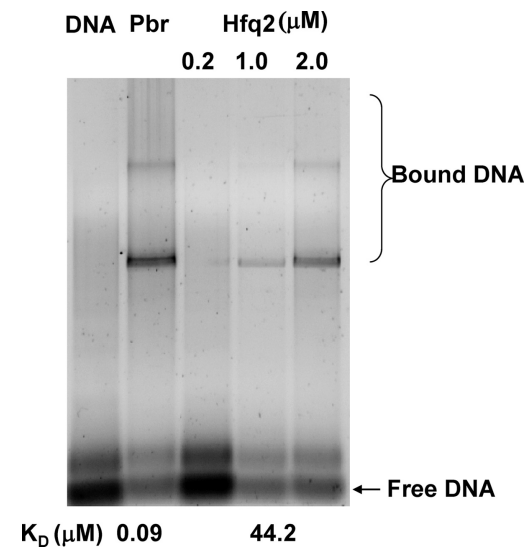

FIG. 6. B. cenocepacia $\mathrm{J} 2315 \mathrm{Hfq} 2$ is able to bind DNA. The ability of Hfq2 to bind DNA was evaluated by band shift assays. The Pbr transcription regulator (28) was used as a positive control. All binding kinetic parameters were calculated by assuming a fixed-term single-site binding isotherm.

$h f q$ or $h f q 2$ by the CJ1 or CJ2 mutant led to numbers of surviving worms comparable to or below those of worms surviving infection by the wild-type strain, a reduction in survival was observed when worms were challenged with the $\mathrm{CJ} 2 \mathrm{mu}-$ tant overexpressing $h f q$.

The total number of CFU surviving within the nematode's digestive tract was consistent with the relative virulence of the wild-type strain, the CJ1 and CJ2 mutants, and the complemented CJ1 and CJ2 mutants (Fig. 9D). Visual inspection of worms infected at 24, 48, or 72 h p.i. with B. cenocepacia $\mathbf{J} 2315$, the $\mathrm{CJ} 2$ mutant, or the complemented $\mathrm{CJ} 2$ mutant showed that worms infected with the CJ2 mutant appeared healthier, in agreement with the requirement of a functional $h f q 2$ gene for the full virulence of B. cenocepacia J2315 (panel E).

\section{DISCUSSION}

Bcc members are among a small number of prokaryotes that encode two distinct copies (highly conserved among Bcc members [27]) of Hfq-like proteins in their genomes, and to the best of our knowledge, this is the first study of a bacterium harboring two distinct and functional Hfq-like proteins.

The similarity found between Hfq 2 and the Sm 1 motif of the $\mathrm{Sm}$ and Lsm proteins from eukaryotes and archaea suggests that these bacterial proteins derive from an ancestral Sm protein (29). In the case of archaea, it was proposed that the ancestral Sm-like protein was subjected to several duplication events, producing the present related Sm-like proteins in yeast, humans, and other eukaryotes (29). Since no significant homology of the C-terminal extension of Hfq2 could be found within other bacterial genome sequence databases besides Bcc, and considering the limited number of bacteria with two distinct Hfq-like genes, we hypothesize that both $h f q$ and $h f q 2$ have arisen in the genomes of Bcc through the duplication of an ancestor gene, followed by evolutionary events that led to two distinct and functional Hfq-like proteins in the current Bcc genomes.

A recent analysis of the genome sequence of $B$. cenocepacia J2315 suggested that this bacterium has recently adapted to the 


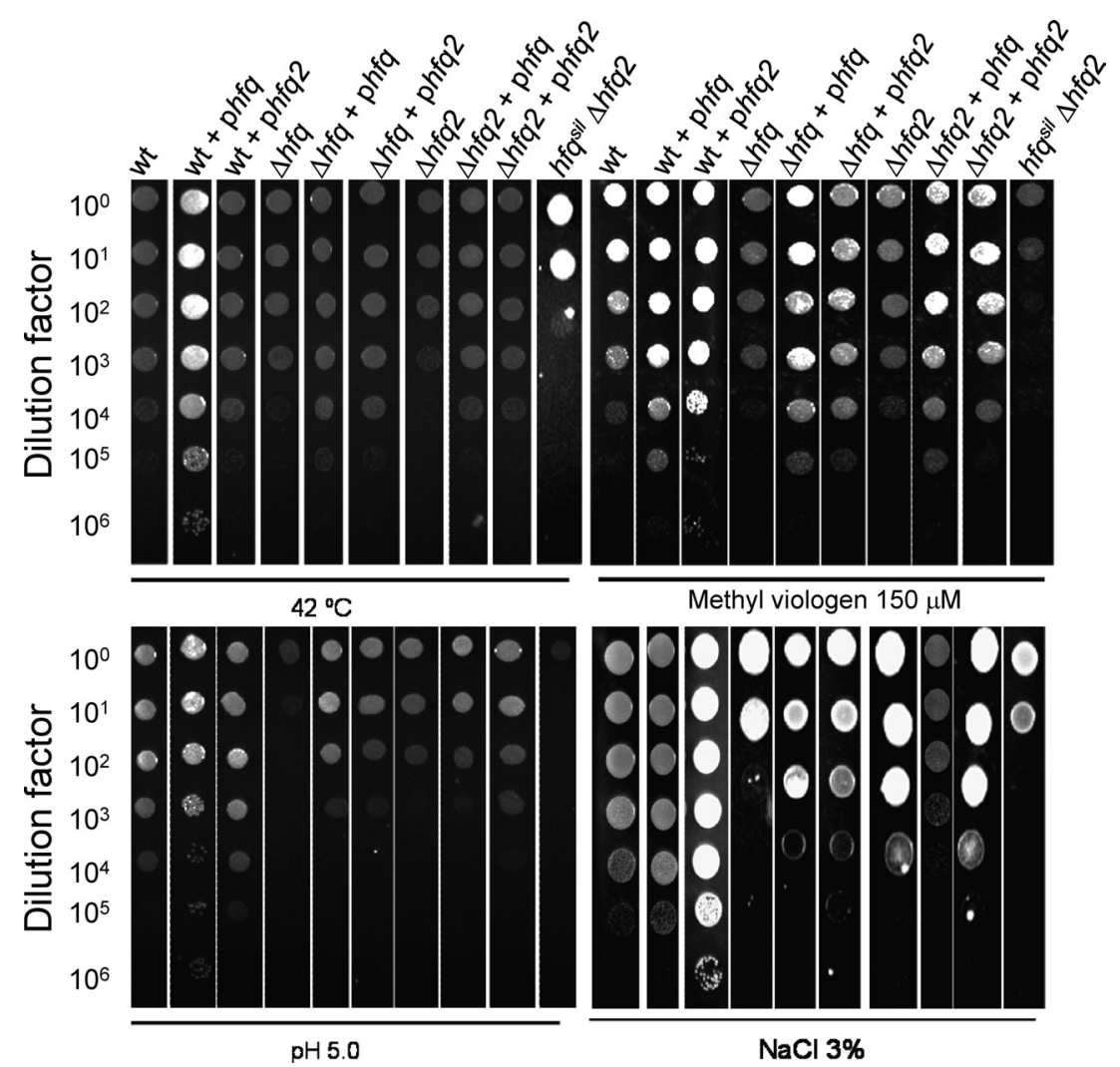

FIG. 7. Both Hfq and Hfq2 are required for stress resistance. The susceptibility of the indicated B. cenocepacia strains to various stresses was tested by spot inoculating serially diluted bacterial suspensions with an initial $\mathrm{OD}_{640}$ of 1.0. wt, wild type.

ecological niche that is the human host, evidenced by a genome well equipped with functions associated with virulence in the CF lung, where the organism must face adverse conditions, including oxidative stress conditions associated with survival within macrophages (12). Our results show that both Hfq-like proteins are required for and contribute to the bacterium's survival of stresses related to the colonization and infection of the CF host, particularly evidenced by the phenotypes of stress susceptibility observed in the CJ3 strain, which harbors a nonfunctional $h f q 2$ gene and expresses an antisense RNA targeting $h f q$. This strain was constructed because we were unable to generate a stable $\Delta h f q \Delta h f q 2$ double mutant.

Interestingly, results also show that overexpression of $h f q$ in the wild-type strain led to increased resistance to $\mathrm{pH} 5.0$ and

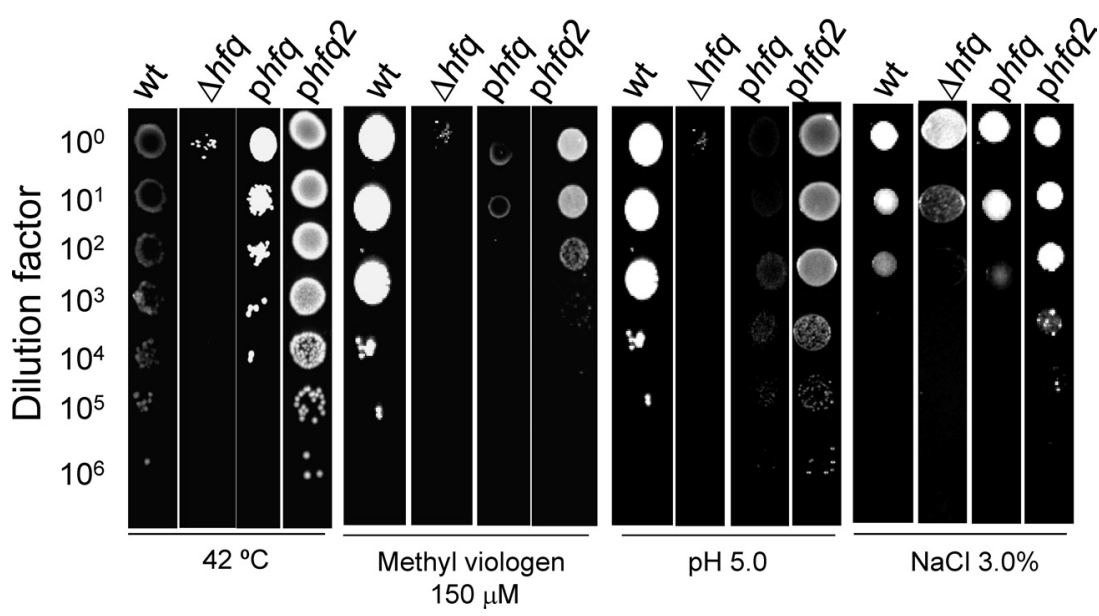

FIG. 8. B. cenocepacia J2315 Hfq and Hfq2 are able to complement an E. coli hfq mutation. The ability of the B. cenocepacia hfq or $h f q 2$ gene to complement the $h f q$ mutation in $E$. coli GS081 was evaluated by subjecting the indicated $E$. coli strains to the stresses indicated. phfq, E. coli GS081 transformed with pSAS3; phfq2, E. coli GS081 transformed with pCGR9; wt, wild type. 

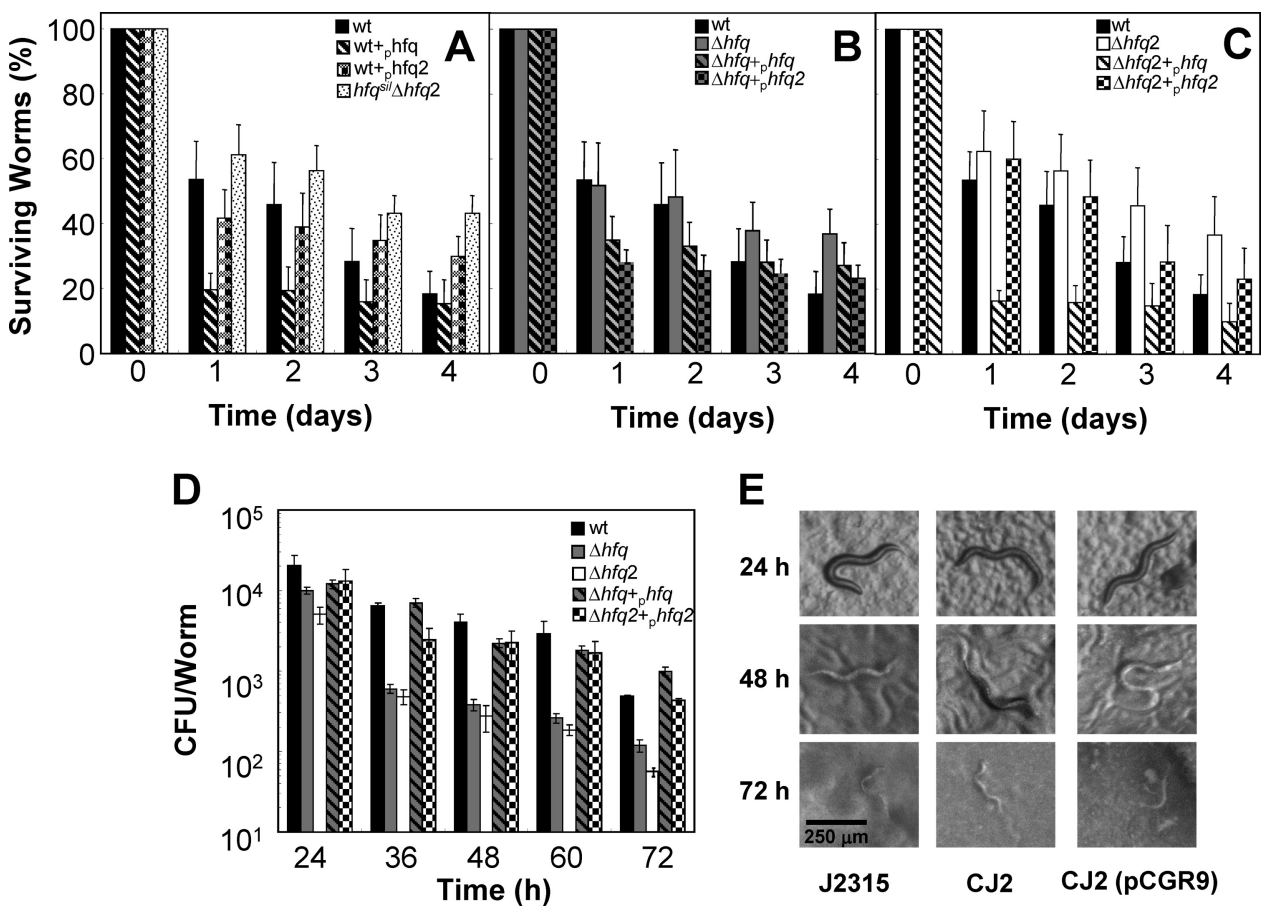

FIG. 9. Hfq and Hfq2 are both required for full B. cenocepacia J2315 virulence in the nematode C. elegans. (A) Abilities of B. cenocepacia wild-type strain J2315 (wt, black bars), J2315 harboring pSAS3 (wt + phfq, dashed bars) or pCGR9 (wt + phfq2, squared bars), and CJ3 (hfq ${ }^{\text {sil }}$ $\Delta h f q 2$, dotted bars) to kill the nematode C. elegans DH26. (B) Abilities of B. cenocepacia $h f q$ mutant CJ1 ( $\Delta h f q$, gray bars) and CJ1 harboring pSA3 $(\Delta h f q+\mathrm{p} h f q$, dashed gray bars) or pCGR9 $(\Delta h f q+\mathrm{p} h f q 2$, squared gray bars) to kill the nematode $C$. elegans DH26. (C) Abilities of the $B$. cenocepacia $h f q 2$ mutant CJ2 $(\Delta h f q 2$, white bars) and CJ2 harboring pSAS3 ( $\Delta h f q 2+$ phfq, dashed bars) or pCGR9 ( $\Delta h f q+$ phfq2, squared bars) to kill the nematode C. elegans DH26. (D) Abilities of B. cenocepacia J2315 (wt, black bars), CJ1 ( $\Delta h f q$, gray bars), CJ2 ( $\Delta h f q 2$, white bars), CJ1 harboring pSA3 $(\Delta h f q+\mathrm{p} h f q$, dashed gray bars), and CJ2 harboring pCGR9 ( $\Delta h f q+$ phfq2, squared bars) to colonize the nematode's digestive tract, expressed as the number of CFU/worm. (E) The health status of worms after infection for 24, 48, or $72 \mathrm{~h}$ with the indicated strains was assessed by visual inspection. Worms in panel $\mathrm{E}$ were randomly chosen and photographed.

$3 \% \mathrm{NaCl}$, while the wild-type strain overexpressing $h f q 2$ exhibited increased resistance to thermal stress and to $150 \mu \mathrm{M}$ methyl viologen. These results suggest that, besides a common role, as evidenced by the ability of both Hfq and Hfq2 to complement an $E$. coli $h f q$ mutant used in this study, each protein might play additional roles related to specific stresses. This specificity possibly derives from the different $\mathrm{C}$ termini of Hfq and Hfq2.

Large Hfq proteins with an extended $\mathrm{C}$ terminus have been described in some bacterial species of the beta- and gammaproteobacteria. Glycine-rich domains between the $\mathrm{N}$ and $\mathrm{C}$ termini (31) have been described for the few large Hfq proteins characterized so far. B. cenocepacia Hfq2 also contains a glycine-rich domain and a repetitive pattern that occurs five times in its $\mathrm{C}$ terminus (27), although no biological function has yet been assigned. A repetitive but distinct pattern was described for Acinetobacter baylyi Hfq which was also found in DnaJ-like chaperones (41), but no functions were attributed to these features of the protein. The biological function of the $\mathrm{C}$ terminus of the 210-amino-acid Hfq protein from Moraxella $\mathrm{ca}$ tarrhalis is also unknown (2).

In the case of E. coli, Veccerek et al. (40) have shown that truncated variants of $\mathrm{Hfq}$ lacking the $\mathrm{C}$-terminal extension, effectively bind sRNAs but are defective in the establishment of sRNA-mRNA base pairing, as well as in Hfq autoregulation, suggesting that the $\mathrm{C}$ terminus constitutes an unrecognized
RNA interaction surface with specificity for mRNAs (40). Although $E$. coli $\mathrm{Hfq}$ and $B$. cenocepacia $\mathrm{Hfq} 2$ are quite distinct, we cannot exclude the possibility that the B. cenocepacia J2315 Hfq2 C terminus plays roles similar to those of the $E$. coli $\mathrm{Hfq}$ $\mathrm{C}$ terminus. A putative DNA binding domain was also identified in the C-terminal extension of Hfq2. Although we present results clearly showing that $\mathrm{Hfq} 2$ is able to bind DNA, both the specificity of the interaction and its biological significance remain unknown. Curiously, a recent report on the ability of $E$. coli Hfq to bind DNA highlighted the importance of the $\mathrm{C}$ terminus in DNA displacement, especially for residues beyond position 75 (38). This amino acid stretch is absent from the $B$. cenocepacia $\mathrm{J} 2315 \mathrm{Hfq}$ protein.

Results of structure prediction and CD spectroscopy experiments indicate that the $\mathrm{Hfq} 2$ glycine-rich $\mathrm{C}$ terminus is predominantly unstructured. We anticipate that this disordered region contributes to the difficulty in assembling the protein into a stable multimeric form greater than three monomers. It is worth noting that this contrasts with the hexameric structures of all of the bacterial small Hfq proteins studied so far (4, 19, 26). Moreover, a recent report by Moskaleva et al. (23) highlights the important role played by histidine residue 57 in the establishment of a stable hexameric structure. Curiously, in B. cenocepacia Hfq2, ${ }^{57} \mathrm{H}$ is replaced by ${ }^{57} \mathrm{R}$, which, together with steric constraints, may account for its inability to form hexamers. 
Given the distinct pattern of regulation of expression observed for the two $h f q$-like genes of B. cenocepacia $\mathrm{J} 2315$, with the RNA levels of $h f q$ maximal in cells in the early exponential phase of growth and the levels of $h f q 2$ RNA being maximal in the stationary phase of growth, it is expected that Hfq and Hfq2 levels must be strictly regulated in the bacterial cell, with this strictly balanced level of the two proteins being required for optimal survival of stress and efficient virulence. Interestingly, our data point out that quorum sensing triggers the expression of $h f q 2$, allowing its maximal expression when $h f q$ mRNA levels are minimal. The differential regulation of $h f q$ and $h f q 2$ might fulfill specific cellular requirements for each of the two proteins in cultures in different growth phases. Our data also suggest that, besides playing the same roles in cell physiology, Hfq and Hfq2 might have distinct functions. This is well illustrated by the increased resistance to high temperature and low $\mathrm{pH}$ conferred by the overexpression of Hfq in wildtype strain J2315 and by the increased resistance of the wildtype strain to osmotic and oxidative stress when overexpressing Hfq2. Both proteins also seem to play somehow distinct roles in virulence. In fact, while Hfq2 overexpression has a more pronounced effect on the rate of C. elegans killing, overexpression of Hfq led to higher numbers of bacterial CFU colonizing the nematode digestive tract. Nevertheless, both proteins are required for virulence, since the simultaneous inactivation of the two Hfq-like proteins results in reduced virulence compared with that of the respective single mutants. Taking these data together and considering the high level of conservation of these proteins in Bcc bacteria, results from this work suggest that although there is a partial redundancy between the functions of these two RNA chaperones, they probably have additional functions in the biology of Bcc bacteria.

Ongoing work envisages the understanding of the specific roles played by each of the two Hfq-like proteins in the expression of genes associated with the stress resistance and virulence of B. cenocepacia J2315.

\section{ACKNOWLEDGMENTS}

We thank the Caenorhabditis Genetics Center (University of Minnesota) for the kind gift of C. elegans DH26, Leo Eberl for B. cenocepacia H111 and H111-cepR, and the Coli Genetic Stock Center (Yale University) for plasmids pKD46, pKD13, and pCP20. We thank A. Azevedo and G. Gomes for help with CD experiments.

This work was supported by Fundação Ciência e Tecnologia, Portugal (contracts PTDC/BIA-MIC/65210/2006 and PTDC/EBB-BIO/ 098352/2008); a postdoctoral grant to S.A.S.; and a Fundação Calouste Gulbenkian doctoral grant to C.G.R.

\section{REFERENCES}

1. Andrade, M. A., P. Chacón, J. J. Merelo, and F. Morán. 1993. Evaluation of secondary structure of proteins from UV circular dichroism using an unsupervised learning neural network. Protein Eng. 6:383-390.

2. Attia, A. S., et al. 2008. Moraxella catarrhalis expresses an unusual Hfq protein. Infect. Immun. 76:2520-2530.

3. Brahms, S., and J. Brahms. 1980. Determination of protein secondary structure in solution by vacuum ultraviolet circular dichroism. J. Mol. Biol. 138 149-178.

4. Brennan, R. G., and T. M. Link. 2007. Hfq structure, function and ligand binding. Curr. Opin. Microbiol. 10:125-133.

5. Brenner, S. 1974. The genetics of Caenorhabditis elegans. Genetics 77:71-94.

6. Casadaban, M. J. 1976. Transposition and fusion of the lac genes to selected promoters in Escherichia coli using bacteriophage lambda and Mu. J. Mol. Biol. 104:541-555.

7. Chao, Y., and J. Vogel. 2010. The role of Hfq in bacterial pathogens. Curr Opin. Microbiol. 13:24-33.

8. Datsenko, K. A., and B. L. Wanner. 2000. One-step inactivation of chromo- somal genes in Escherichia coli K-12 using PCR products. Proc. Natl. Acad Sci. U. S. A. 97:6640-6645.

9. Gottesman, S. 2004. The small RNA regulators in Escherichia coli: roles and mechanisms. Annu. Rev. Microbiol. 58:303-328.

10. Govan, J. R., and V. Deretic. 1996. Microbial pathogenesis in cystic fibrosis mucoid Pseudomonas aeruginosa and Burkholderia cepacia. Microbiol. Rev. 60:539-574.

11. Govan, J. R. W., et al. 1993. Evidence for transmission of Pseudomonas cepacia by social contact in cystic fibrosis. Lancet 342:15-19.

12. Holden, M. T., et al. 2009. The genome of Burkholderia cenocepacia $\mathrm{J} 2315$, an epidemic pathogen of cystic fibrosis patients. J. Bacteriol 191:261-277.

13. Kajitani, M., A. Kato, A. Wada, Y. Inokuchi, and A. Ishihama. 1994. Regulation of the Escherichia coli hfq gene encoding the host factor for phage $\mathrm{Q}_{\beta}$. J. Bacteriol. 176:531-534.

14. Kawano, M., A. A. Reynolds, J. Miranda-Rios, and G. Storz. 2005. Detection of 5' - and 3'-UTR-derived small RNAs and cis-encoded antisense RNAs in Escherichia coli. Nucleic Acids Res. 33:1040-1050.

15. Köthe, M., et al. 2003. Killing of Caenorhabditis elegans by Burkholderia cepacia is controlled by the cep quorum-sensing system. Cell. Microbiol. 5:343-351.

16. Lagos-Quintana, M., R. Rauhut, W. Lendeckel, and T. Tuschl. 2001. Identification of novel genes coding for small expressed RNAs. Science 294:853858 .

17. Lefebre, M. D., and M. A. Valvano. 2002. Construction and evaluation of plasmid vectors optimized for constitutive and regulated gene expression in Burkholderia cepacia complex isolates. Appl. Environ. Microbiol. 68:59565964.

18. Leitão, J. H., et al. 2010. Pathogenicity, virulence factors, and strategies to fight against Burkholderia cepacia complex pathogens and related species. Appl. Microbiol. Biotechnol. 87:31-40.

19. Link, T. M., P. Valentin-Hansen, and R. G. Brennan. 2009. Structure of Escherichia coli Hfq bound to polyriboadenylate RNA. Proc. Natl. Acad. Sci. U. S. A. 106:19292-19297.

20. Meselson, M., and R. Yuan. 1968. DNA restriction enzyme from E. coli. Nature 217:1110-1114.

21. Møller, T., et al. 2002. Hfq: a bacterial Sm-like protein that mediates RNARNA interaction. Mol. Cell 9:23-30.

22. Moreira, L. M., et al. 2003. Identification and physical organization of the gene cluster involved in the biosynthesis of Burkholderia cepacia complex exopolysaccharide. Biochem. Biophys. Res. Commun. 312:323-333.

23. Moskaleva, O., et al. 2010. The structures of mutant forms of Hfq from Pseudomonas aeruginosa reveal the importance of the conserved His57 for the protein hexamer organization. Acta Crystallogr. Sect. F Struct. Biol Cryst. Commun. 66(Pt. 7):760-764.

24. Münch, R., et al. 2005. Virtual Footprint and PRODORIC: an integrative framework for regulon prediction in prokaryotes. Bioinformatics 21:41874189.

25. Papenfort, K., and J. Vogel. 2010. Regulatory RNA in bacterial pathogens. Cell Host Microbe 8:116-127.

26. Rajkowitsch, L., and R. Schroeder. 2007. Dissecting RNA chaperone activity. RNA 13:2053-2060.

27. Ramos, C. G., A. M. Grilo, and J. H. Leitão. 2010. Small non-coding RNAs in prokaryotes: roles in pathogenesis and potential therapeutic targets. Lambert Academic Publishing, Saarbrücken, Germany.

28. Ramos, C. G., S. A. Sousa, A. M. Grilo, L. Eberl, and J. H. Leitão. 2010. The Burkholderia cenocepacia K56-2 pleiotropic regulator $\mathrm{Pbr}$, is required for stress resistance and virulence. Microb. Pathog. 48:168-177.

29. Salgado-Garrido, J., E. Bragado-Nilsson, S. Kandels-Lewis, and B. Séraphin. 1999. Sm and Sm-like proteins assemble in two related complexes of deep evolutionary origin. EMBO J. 18:3451-3462.

30. Sambrook, J., and D. W. Russell. 2001. Molecular cloning: a laboratory manual, 3rd ed. Cold Spring Harbor Laboratory Press, Cold Spring Harbor, NY.

31. Schilling, D., and U. Gerischer. 2009. The Acinetobacter baylyi hfq gene encodes a large protein with an unusual C terminus. J. Bacteriol. 191:55535562 .

32. Schirmer, F., S. Ehrt, and W. Hillen. 1997. Expression, inducer spectrum, domain structure, and function of MopR, the regulator of phenol degradation in Acinetobacter calcoaceticus NCIB8250. J. Bacteriol. 179:1329 1336.

33. Sousa, S. A., L. M. Moreira, and J. H. Leitão. 2008. Functional analysis of the Burkholderia cenocepacia J2315 BceAJ protein with phosphomannose isomerase and GDP-D-mannose pyrophosphorylase activities. Appl. Microbiol. Biotechnol. 80:1015-1022.

34. Sousa, S. A., et al. 2007. The Burkholderia cepacia bceA gene encodes a protein with phosphomannose isomerase and GDP-D-mannose pyrophosphorylase activities. Biochem. Biophys. Res. Commun. 353:200-206.

35. Sousa, S. A., C. G. Ramos, and J. H. Leitão. 2011. Burkholderia cepacia complex: emerging multihost pathogens equipped with a wide range of virulence factors and determinants. Int. J. Microbiol. 2011:607575.

36. Sousa, S. A., C. G. Ramos, L. M. Moreira, and J. H. Leitão. 2010. The $h f q$ 
gene is required for stress resistance and full virulence of Burkholderia cepacia to the nematode Caenorhabditis elegans. Microbiology 156:896908.

37. Sutherland, B. W., J. Toews, and J. Kast. 2008. Utility of formaldehyde cross-linking and mass spectrometry in the study of protein-protein interactions. J. Mass Spectrom. 43:699-715.

38. Updegrove, T. B., J. J. Correia, R. Galletto, W. Bujalowski, and R. M. Wartell. 2010. E. coli DNA associated with isolated Hfq interacts with Hfq's distal surface and C-terminal domain. Biochim. Biophys. Acta 1799:588-596.

39. Valentin-Hansen, P., M. Eriksen, and C. Udesen. 2004. The bacterial Smlike protein Hfq: a key player in RNA transactions. Mol. Microbiol. 51:15251533.
40. Veccerek, B., L. Rajkowitsch, E. Sonnleitner, R. Schroeder, and U. Blasi. 2008. The C-terminal domain of Escherichia coli Hfq is required for regulation. Nucleic Acids Res. 36:133-143.

41. Walsh, P., D. Bursa, Y. C. Law, D. Cyr, and T. Lithgow. 2004. The J-protein family: modulating protein assembly, disassembly and translocation. EMBO Rep. 5:567-571.

42. Williams, P., and M. Cámara. 2009. Quorum sensing and environmental adaptation in Pseudomonas aeruginosa: a tale of regulatory networks and multifunctional signal molecules. Curr. Opin. Microbiol. 12:182-191.

43. Zhang, A., K. M. Wassarman, J. Ortega, A. C. Steven, and G. Storz. 2002. The Sm-like Hfq protein increases OxyS RNA interaction with target mRNAs. Mol. Cell 9:11-22. 